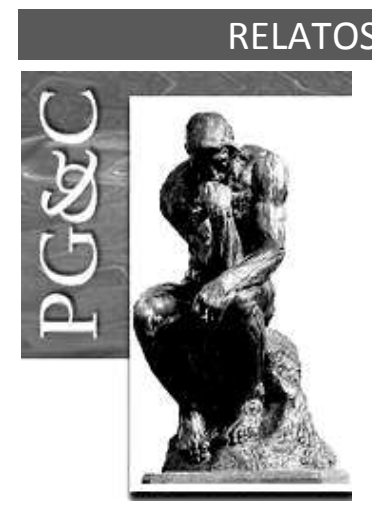

\title{
'FAÇA O QUE EU DIGO E FAÇA O QUE EU FAÇO': COMO PEQUENOS EMPREENDEDORES DE SOFTWARE PERCEBEM A INOVAÇÃO EM SUAS EMPRESAS
}

\author{
Hilka Pelizza Vier Machado \\ Doutora em Engenharia de Produção pela Universidade Federal de Santa \\ Catarina, Brasil. Professora da Universidade Cesumar e da Universidade do \\ Oeste de Santa Catarina, Brasil. \\ E-mail: hilkavier@yahoo.com \\ Nelson Tenório \\ Doutor em Ciência da Computação pela Pontifícia Universidade Católica \\ do Rio Grande do Sul, Brasil. Professor da Universidade Cesumar, Brasil. \\ E-mail: nelson.tenoriojr@gmail.com
}

\begin{abstract}
Resumo
O objetivo deste estudo foi compreender como pequenas empresas de software lidam com a questão do conhecimento e da inovação e qual o apoio que recebem para buscar inovação. Metodologia: para atingir esse objetivo, foi realizado um estudo exploratório, qualitativo, junto a quatro pequenas empresas de software. Os dados foram coletados por meio de entrevistas e dados secundários. Os resultados mostraram que os empresários atribuem importância à inovação. Como variáveis internas para inovação foram apontadas: redes, projetos e prêmios, retenção de pessoal e cultura de inovação. Como variável externa foi mencionada a necessidade de políticas de apoio ao setor. Eles mencionaram também dificuldade para inovar, principalmente quanto ao tempo necessário para desenvolver os produtos. Conclusão: Os resultados apresentam uma compreensão dos desafios e limitações de pequenas empresas de software em relação à gestão interna da inovação e do conhecimento, importante para produzir inovação para o mercado.
\end{abstract}

Palavras-chave: Inovação. Gestão do Conhecimento. Empresas de software.

\section{DO WHAT I SAY AND DO WHAT I DO: HOW SMALL SOFTWARE ENTREPRENEURS PERCEIVE INNOVATION IN THEIR COMPANIES.}

\begin{abstract}
The aim of this study was to understand how small software companies deal with the issue of knowledge and innovation and what support they receive to seek innovation. Methodology: to achieve this objective, an exploratory, qualitative study was conducted with four small software companies. The data were collected through interviews and secondary data. The results showed that entrepreneurs attach importance to innovation. Internal variables for innovation were networks, projects and awards, retention of personnel and culture of innovation. As an external variable, the need for policies to support the sector was mentioned. They also mentioned difficulty to innovate, mainly as to the time needed to develop the products. Conclusion: The results present an understanding of the challenges and limitations of small software companies in relation to internal management of innovation and knowledge, important to produce innovation for the market.
\end{abstract}

Keywords: Innovation. Knowledge Management. Soft Enterprises.

Perspectivas em Gestão \& Conhecimento, João Pessoa, v. 11, número especial, p. 131-145, mar. 2021. DOI: http://dx.doi.org/10.22478/ufpb.2236-417X.2021v11nEspecial.57567

http://periodicos.ufpb.br/ojs2/index.php/pgc. ISSN: 2236-417X. Publicação sob Licença (cc) EY-NC-ND 


\section{INTRODUÇÃO}

O setor de software é relevante para o contexto brasileiro. Ele abrange um grande número de empresas. O país ocupa a nona posição no ranking mundial, com 17.000 empresas no setor de tecnologia da informação sendo 5.294 especificamente de produção de software. Além disso, considerando as empresas que atuam no desenvolvimento de software, pouco mais de $95 \%$ podem ser classificadas como micro e pequenas empresas (ABES, 2018). Ao desenvolver softwares para outras empresas elas colaboram com a inovação de seus clientes.

As empresas que atuam com o desenvolvimento de software, que constitui uma atividade intensiva em conhecimento (ROBILLARD, 1999), geram soluções para outras empresas dos mais diversos setores. Portanto, as empresas de software necessitam atuar com o desenvolvimento de seus produtos e isso representa um desafio que requer habilidade para inovar (LEITE; MORAES, 2015). Por sua vez, para inovar, essas mesmas empresas precisam gerir o conhecimento (SALAZAR, 2020). Com isso, o conhecimento para empresas de software é inerente ao processo de gestão.

Diferentes aspectos foram abordados em estudos anteriores sobre empresas de software no Brasil. Entre os estudos disponíveis em bases nacionais como Spell e Scielo foram identificados estudos referentes à obtenção de conhecimentos a partir de experiências de internacionalização (GASQUEZ, MACHADO; URPÍA, 2020); capacidades inovadoras (MIRANDA; FIGUEIREDO, 2010); crescimento das empresas (MACHADO, 2018); memória e inovação (KAUFMANN et al., 2019), entre outros. Não foram identificados estudos que abordaram a visão de empreendedores de software sobre a inovação em suas empresas e sobre o apoio recebido.

Desse modo, considerando que empresas de software oferecem serviços e facilitam o conhecimento para outras empresas inovarem e, ainda, que 95\% dos empreendedores são caracterizados como micro e pequenas empresas de desenvolvimento de software, é importante conhecer como elas lidam com a questão do conhecimento e da inovação. Portanto, o que a inovação significa para essas pequenas empresas de software? Com qual apoio elas contam para inovar e desenvolver novos conhecimentos? Para responder essas questões, elaborou-se o presente estudo que teve como objetivo compreender como pequenas empresas de software lidam com a questão do conhecimento e da inovação e qual o apoio que recebem para buscar inovação. Para isso, foi realizado um estudo qualitativo, com estudos de casos múltiplos.

A estrutura do trabalho é constituída por esta introdução, por um referencial teórico que apresentou os preceitos teóricos que balizaram o trabalho e as análises, seguido da descrição dos procedimentos metodológicos. Na sequência, foram apresentados os resultados e discussões e, finalmente, as conclusões, destacando contribuições e sugestões para futuros estudos.

\section{REFERENCIAL TEÓRICO}

\subsection{Conhecimento e Inovação em empresas de software}

A inovação está associada a novos produtos ou serviços que apresentem ineditismo, bem como a novos processos de produção e novos mercados (SCHUMPETER, 1934). De acordo com o entendimento da Organisation for Economic Co-operation and Development (OECD, 2018), a inovação implica em algo novo ou melhorado no produto ou processo (ou ambos).

Perspectivas em Gestão \& Conhecimento, João Pessoa, v. 11, número especial, p. 131-145, mar. 2021. 
Especificamente no setor de serviços, a inovação consiste em obter desempenho superior por meio da proposição de valor (LEO; TELLO-GAMARRA, 2020).

O conhecimento é um ativo para empresas de software e o gerenciamento dele é importante para que elas previnam a perda de conhecimento (LEVALLET; CHAN, 2019). O conhecimento deriva de dados e informações, ele representa a informação combinada com a experiência, contexto, interpretação e reflexão (BASAÑEZ, 2014). Nesse sentido, o conhecimento pode ser compreendido como uma estrutura permanente de informação armazenada na memória das organizações (ROBILLARD, 1999).

Robillard (1999) salienta que o conhecimento pode ser: a) procedural, derivado de habilidades motoras e de competências desenvolvidas na interação com o ambiente. Este tipo de conhecimento é raramente esquecido e constitui o que denominamos know-how; b) declarativo, baseado em fatos, pessoas, e eventos e seus relacionamentos. A memória declarativa abrange conhecimentos tópicos, semânticos ou episódicos. Conhecimentos tópicos, por sua vez, referem-se a significados de palavras e definições, identificados no nível social, pessoal, profissional e técnico. Conhecimento episódico está associada a alguma experiencia com conhecimento. As empresas de software necessitam de conhecimentos tópicos e episódicos. Massago et al. (2019) salientam que o desenvolvimento de software é influenciado por aspectos socioculturais, corroborando a influência de conhecimentos episódicos.

A gestão do conhecimento em empresas de software impulsiona a aprendizagem organizacional e torna possível a difusão de melhores práticas dentro da organização, assim como a definição e o estabelecimento de processos. Além disso, a gestão do conhecimento favorece a constituição de redes de trabalho internas entre as áreas da empresa e uma plataforma comum de interação entre as áreas para que elas possam compartilhar informações e gerar conhecimento e inovação (RIVERO, 2010). As empresas de desenvolvimento de software constroem soluções para os mais diversos setores que exigem confiabilidade, visibilidade e rastreabilidade do projeto de software para garantir um produto que atenda às necessidades do cliente (LAUKKARINEN, KUUSINEN; MIKKONEN, 2018). Nesse contexto, gerenciar o conhecimento na indústria de software torna-se crucial, principalmente por essas organizações produzirem informações de modo constante e possuindo características complexas e dinâmicas (NAWINNA, 2011).

Empresas de software podem adotar diferentes estratégias para gerar e compartilhar o conhecimento: a) repositórios e livrarias do conhecimento, que servem para documentar o conhecimento tácito, registrar o conhecimento existente; b) ferramentas da comunidade de trabalhadores: mecanismos que distribuem as tarefas, documentam projetos; c) cartografia do conhecimento, uma ferramenta para mapear e categorizar o conhecimento, reconhecendo as informações disponíveis nas empresas e; d) fluxo do conhecimento, uma ferramenta que permite a interação das anteriores entre os diferentes tipos de conhecimento (RIVERO, 2010).

Para promover a inovação, empresas de software precisam desenvolver competências, explorando conhecimento tácito e codificando o conhecimento (OECD, 1996). A memória exerce um papel importante no processo de inovação dessas empresas, como Kaufmann et al. (2019) demonstraram, ao pesquisarem 800 empresas de software no Brasil. Além da memória, os autores identificaram que a capacidade inovativa dessas empresas depende ainda de fatores como liderança, cultura, estratégia, estrutura, processos, pessoas, relacionamentos, infraestrutura tecnológica, mensuração e desempenho.

Miranda e Figueiredo (2010) ressaltam a importância de mensurar da inovação. Eles classificaram as empresas de software em diferentes níveis de inovação, conforme detalhado no Quadro 1. Para o nível avançado de inovação, as empresas teriam que desenvolver softwares integrando diferentes áreas de conhecimento, com equipes geograficamente distantes, produzindo tendência de ponta. Para isso, elas teriam que continuamente aprimorar 
os processos de produção. No nível intermediário, as empresas trabalham mais com a integração das ferramentas e com frameworks de desenvolvimento de software. Ainda assim, apresentam soluções de alto valor agregado e elevada complexidade, controlando processos com métricas de qualidade. No nível de inovação básica, as empresas trabalham voltadas para o desenvolvimento de soluções para os clientes, adaptando ferramentas de produção de software.

Quadro 1- Classificação para análise de capacidades tecnológicas em empresas de software

\begin{tabular}{|c|c|c|c|}
\hline Nível de inovação & Software & Produtos e serviços & Processos \\
\hline $\begin{array}{l}\text { Inovação Avançada } \\
\text { (próxima à fronteira } \\
\text { internacional) }\end{array}$ & $\begin{array}{l}\text { Ferramentas próprias de } \\
\text { engenharia de software; } \\
\text { integração com ferramentas } \\
\text { de outras áreas de } \\
\text { conhecimento, como Geo- } \\
\text { posicionamento e Telecom; } \\
\text { ferramentas geradoras de } \\
\text { código; e equipes } \\
\text { geograficamente distantes. }\end{array}$ & $\begin{array}{lr}\text { Serviços de } & \text { P\&D } \\
\text { com tecnologias e } \\
\text { tendências de ponta, } \\
\text { como } \\
\text { computing, } \\
\text { convergência } \\
\text { mídias e TV Digital } \\
\text { [S]; e P\&D com } \\
\text { tecnologias } \\
\text { ponta, visando ao } \\
\text { lançamento } \\
\text { produtos inovadores } \\
\text { e difíceis de copiar } \\
\text { [P]. }\end{array}$ & $\begin{array}{l}\text { Aprimoramento } \\
\text { contínuo dos processos, } \\
\text { tanto a partir de } \\
\text { avanços incrementais } \\
\text { nos processos } \\
\text { existentes quanto a } \\
\text { partir de novos } \\
\text { métodos e tecnologias }\end{array}$ \\
\hline $\begin{array}{l}\text { Inovação } \\
\text { intermediária }\end{array}$ & $\begin{array}{l}\text { Integração das ferramentas } \\
\text { de engenharia; ferramentas } \\
\text { automatizadas de inspeção } \\
\text { de código e testes de } \\
\text { software; equipes } \\
\text { multidisciplinares integradas } \\
\text { e ferramentas de } \\
\text { colaboração; técnicas de } \\
\text { geração de versões diárias; e } \\
\text { frameworks de } \\
\text { desenvolvimento } \\
\text { software. }\end{array}$ & $\begin{array}{l}\text { Soluções de alto } \\
\text { valor agregado e alta } \\
\text { complexidade } \\
\text { conhecimento } \\
\text { técnico e de } \\
\text { negócios } \\
\text { soluções completas } \\
\text { com integração e } \\
\text { personalização de } \\
\text { software corporativo } \\
\text { [S]; utilização de } \\
\text { tecnologias de } \\
\text { ponta, como RFID } \\
\text { (b); reconhecimento } \\
\text { de voz, para criar } \\
\text { produtos capazes de } \\
\text { gerar demanda [P]. }\end{array}$ & $\begin{array}{lr}\text { Os } & \text { processos } \\
\text { controlados } & \text { com } \\
\text { métricas de qualidade. } \\
\text { A estrutura das } \\
\text { empresas é adaptada } \\
\text { ao processo. } \\
\text { Automatização de } \\
\text { etapas cruciais do } \\
\text { processo, como testes } \\
\text { unitários e controle de } \\
\text { versão. }\end{array}$ \\
\hline Inovação básica & $\begin{array}{l}\text { Adaptações das ferramentas } \\
\text { de engenharia; padronização } \\
\text { das práticas de teste e } \\
\text { inspeção de código; } \\
\text { interação com fornecedores, } \\
\text { clientes e parceiros; criação } \\
\text { e controle de versões } \\
\text { automatizadas; técnicas } \\
\text { avançadas de controle de } \\
\text { versão; e criação de } \\
\text { biblioteca de componentes. }\end{array}$ & 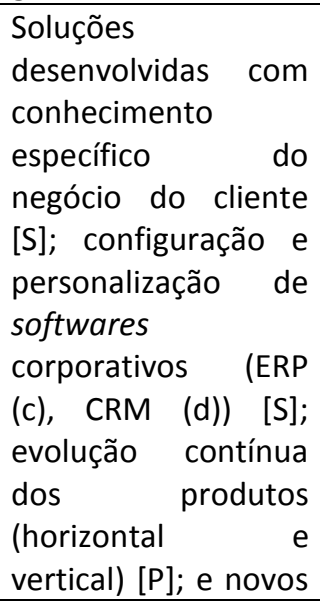 &  \\
\hline
\end{tabular}

Perspectivas em Gestão \& Conhecimento, João Pessoa, v. 11, número especial, p. 131-145, mar. 2021. 


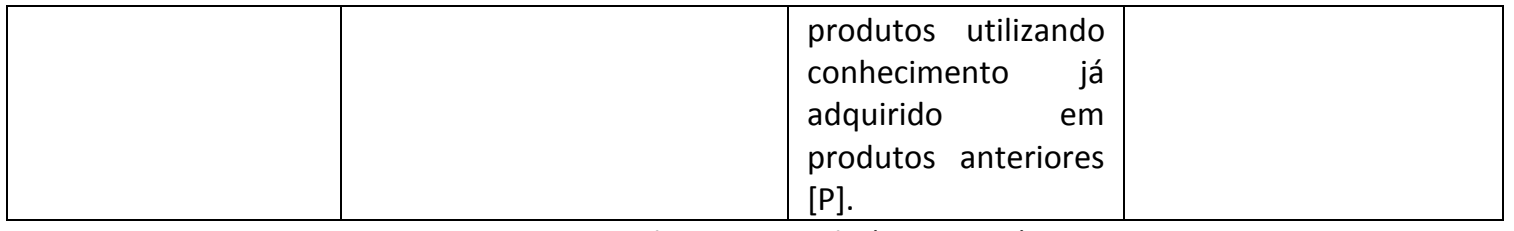

Fonte: Miranda e Figueiredo (2010, p. 8)

As empresas de software, como se observa no Quadro 1, podem apresentar diferentes níveis de inovação tecnológica. Para atingir esses níveis, elas precisam gerir o processo de inovação constantemente, atentando não apenas para questões de ordem técnica, mas também para aspectos da cultura da organização, da participação em redes, da definição de estratégias, entre outros aspectos.

A inovação pode derivar de modelos tais como a hélice tripla, inovação aberta, ou modelos integrados e em redes (SALAZAR, 2020). Modelos integrados resultam da formação de equipes multidisciplinares para o desenvolvimento de um produto que se desenvolve a partir do compartilhamento do conhecimento, como preconizaram Nonaka e Takeuchi (Salazar, 2020). Os modelos em redes são importantes para busca de conhecimento externo pelos empreendedores. As redes podem auxiliar na seleção dos mercados e na velocidade de entrada dos mercados (IBEH; KASEM, 2011). Além disso, Salazar (2020) salienta a importância da vigilância tecnológica. Outro aspecto importante no processo de inovação é a relação com universidades, para transferência do conhecimento (DINIZ et al., 2020; OECD, 1996). Outro modelo é sugerido por Leo e Tello-Gamarra (2020), abrangendo quatro determinantes internas: cultura organizacional, estratégias, capital humano e pesquisa e desenvolvimento (P\&D) e determinantes externas: trajetória institucional, em termos de evolução das regulações e das instituições políticas e públicas, e os atores (competidores, clientes e fornecedores). Por sua vez, o modelo Bezerra e Marques (2019) propicia a avaliação do conhecimento e inovação é suas dimensões estão sintetizadas no Quadro 2.

Quadro 2 - Síntese das dimensões de avaliação de conhecimento e inovação

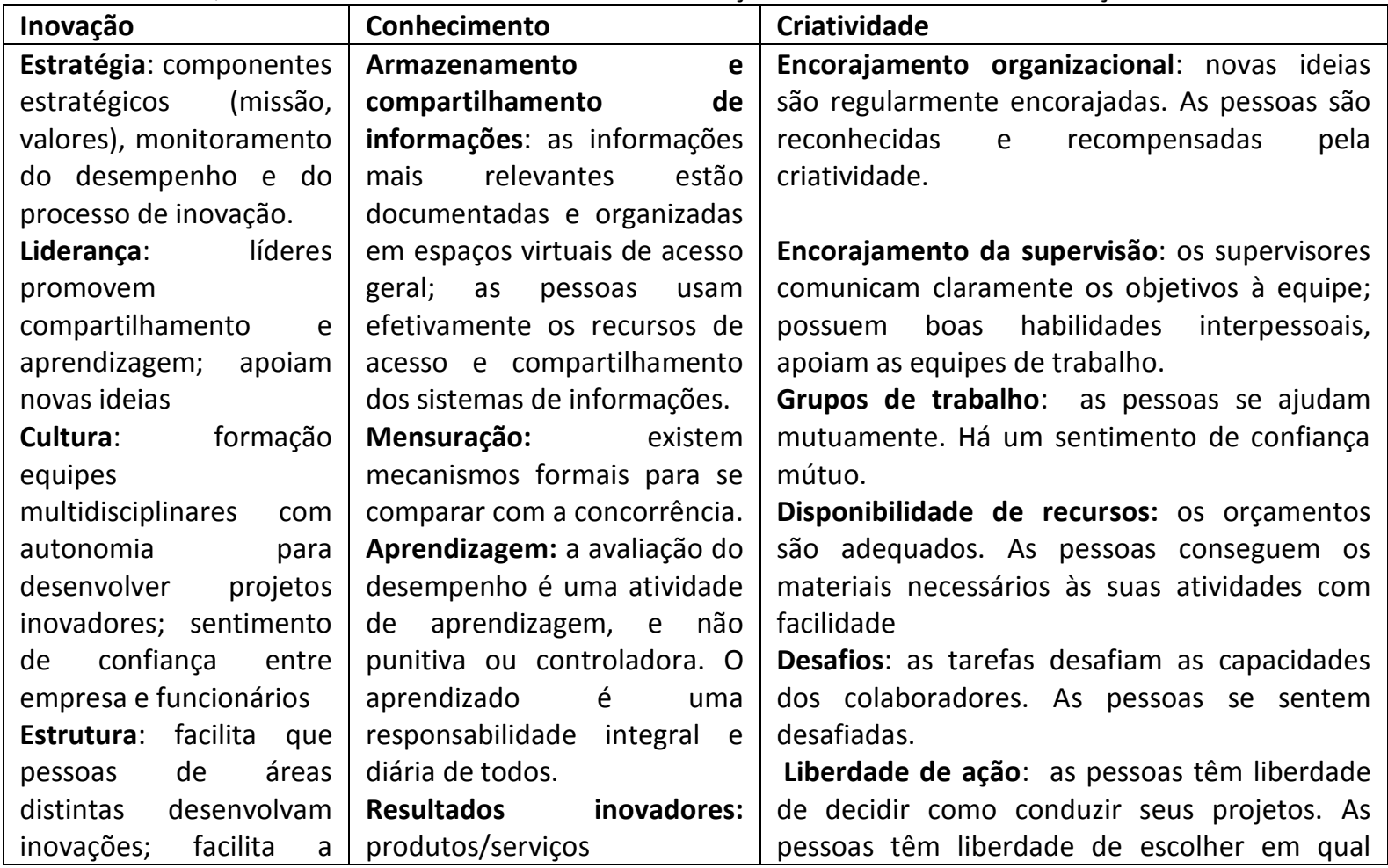

Perspectivas em Gestão \& Conhecimento, João Pessoa, v. 11, número especial, p. 131-145, mar. 2021. 


\begin{tabular}{|c|c|c|}
\hline  & 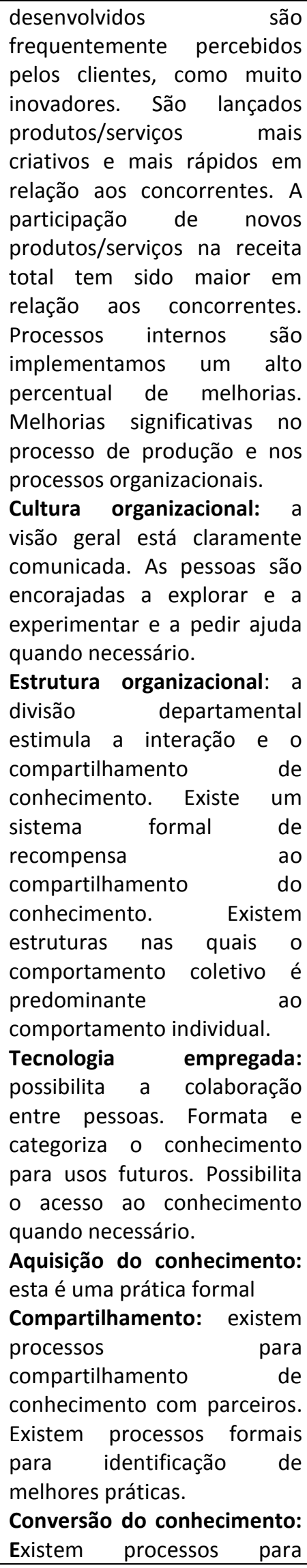 & $\begin{array}{l}\text { projeto irão participar. } \\
\text { Impedimentos organizacionais: existem } \\
\text { problemas políticos, as pessoas são resistentes } \\
\text { às novas ideias, existem competições que } \\
\text { podem ser destrutivas. A alta gerência não } \\
\text { assume riscos. } \\
\text { Carga de trabalho: existe uma forte pressão em } \\
\text { relação aos prazos. As expectativas são } \\
\text { realistas em relação aos objetivos traçados. }\end{array}$ \\
\hline
\end{tabular}

Perspectivas em Gestão \& Conhecimento, João Pessoa, v. 11, número especial, p. 131-145, mar. 2021. 


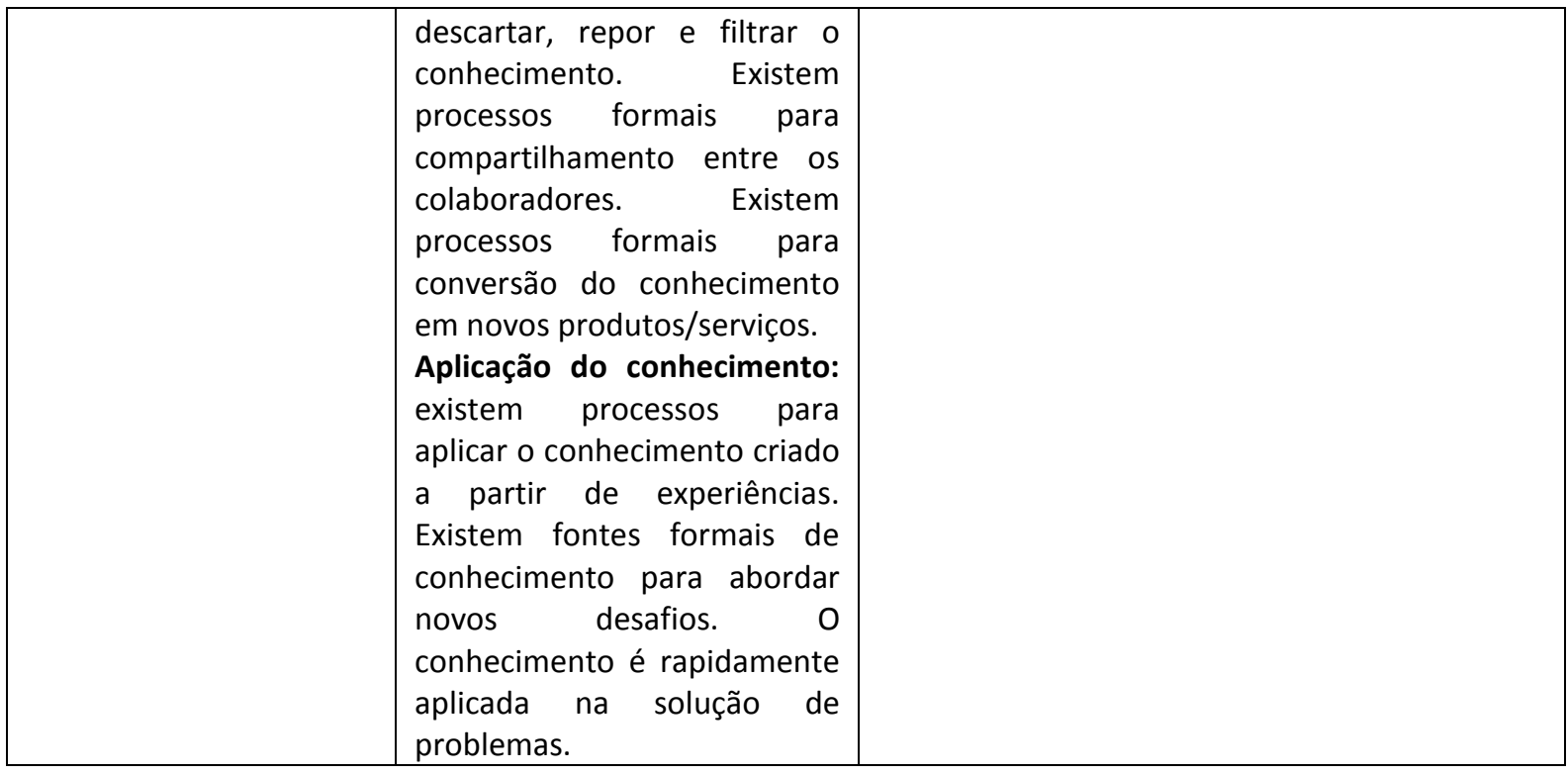

Fonte: Bezerra e Marques (2019)

\section{METODOLOGIA}

Esta pesquisa é um estudo qualitativo, exploratório, que propiciou um conhecimento contextualizado da inovação de pequenas empresas de software. A pesquisa qualitativa "proporciona profundidade aos dados, dispersão, riqueza interpretativa, contextualização do ambiente ou entorno, detalhes e experiências únicas" (SAMPIERI, COLLADO; LUCIO, 2013, p. 41). O método foi o estudo de caso, especificamente casos múltiplos, seguindo a lógica da replicação (YIN, 2015). A unidade de análise será constituída pelos empreendedores que criaram as empresas.

Para identificação das empresas, foi realizado um contato junto a uma associação local de empresas de software. Após contatos com empreendedores, quatro empresas pequenas se dispuseram a participar do estudo. Para fins de confidencialidade, as empresas aqui são denominadas A, B, C e D.

Os dados foram coletados, inicialmente dados primários, obtidos por meio de entrevistas junto aos empreendedores. Foram realizadas quatro entrevistas abertas em profundidade, para os empreendedores falarem sobre o conhecimento e a inovação em suas atividades. $A$ entrevista do caso $A$ teve a duração de uma hora e doze minutos, a do caso $B, 50$ minutos, a do $C, 42$ minutos e a $D$ uma hora e dois minutos. Elas foram realizadas nas empresas, após o consentimento e a assinatura de termo de esclarecimento e livre consentimento. Todas foram gravadas e, posteriormente, transcritas. Em seguida, as transcrições foram enviadas por e-mail para os entrevistados validaram o conteúdo. Não foram realizadas alterações nas transcrições.

Além de dados primários, foram também coletados dados secundários, por meio de informações junto ao site das referidas empresas. Na sequência, as transcrições e os dados secundários foram importadas para o software NVivo, para serem codificados e categorizados. 
Quadro 3- Protocolo dos Estudos de Caso

\begin{tabular}{|c|c|}
\hline \multicolumn{2}{|l|}{ Visão geral do Estudo } \\
\hline Objetivo & $\begin{array}{l}\text { Compreender como pequenas empresas de software lidam com a } \\
\text { questão do conhecimento e da inovação e qual o apoio que } \\
\text { recebem para buscar inovação. }\end{array}$ \\
\hline Tipo de Estudo & Estudos de Casos múltiplos. \\
\hline \multicolumn{2}{|c|}{$\begin{array}{l}\text { Procedimentos de coleta de } \\
\text { dados }\end{array}$} \\
\hline Seleção dos casos & $\begin{array}{l}\text { Conveniência em função da natureza do estudo, foram } \\
\text { selecionados } 4 \text { casos. }\end{array}$ \\
\hline Procedimentos & $\begin{array}{l}\text { Elaboração de Termo de consentimento e livre esclarecimento } \\
\text { para as entrevistas. Coleta de dados secundários nos sites das } \\
\text { empresas. }\end{array}$ \\
\hline Entrevistas abertas & Gravação das entrevistas, transcrição e envio por e-mail. \\
\hline Questões & $\begin{array}{l}\text { Descreva e comente sobre o conhecimento e a inovação em suas } \\
\text { atividades }\end{array}$ \\
\hline Análise & $\begin{array}{l}\text { Dados foram tratados “a partir do zero" (Yin, 2015) e em seguida } \\
\text { foi realizada a análise de conteúdo do corpus do texto (Bardin, } \\
\text { 2010). }\end{array}$ \\
\hline
\end{tabular}

Fonte: Elaborado pelos autores com base em Yin (2015)

A análise de conteúdo dos dados (BARDIN, 2011) teve início com uma leitura flutuante, que propiciou uma compreensão geral dos sentidos atribuídos pelos empreendedores para o conhecimento e inovação. Então, a partir do critério semântico, foram extraídos dos textos os trechos associados às questões de pesquisa, os quais foram codificados e agrupados, gerando as categorias de análise.

\section{RESULTADOS E DISCUSSÃO}

Para fins de contextualização, a Tabela 1 apresenta o perfil de cada um dos entrevistados. Pode se observar que todos os empreendedores apresentam uma experiência com outras empresas e apenas um deles não tem experiência na área técnica de TI.

Tabela 1: Perfil dos entrevistados

\begin{tabular}{l|l|l|l|l}
\hline Caso & Idade & Sexo & Escolaridade & Experiência Anterior \\
\hline A & 40 & masculino & $\begin{array}{l}\text { Mestre em ciência da } \\
\text { Computação }\end{array}$ & $\begin{array}{l}\text { Teve outras empresas em outra } \\
\text { área }\end{array}$ \\
\hline B & 38 & masculino & Engenharia de Software & $\begin{array}{l}\text { Abriu uma outra empresa que } \\
\text { não deu certo }\end{array}$ \\
\hline C & 40 & masculino & Ciência da Computação & Tinha outra empresa que fechou \\
\hline D & 37 & masculino & $\begin{array}{l}\text { História e MBA em } \\
\text { Gestão Empresarial }\end{array}$ & Teve outra empresa que fechou \\
\hline
\end{tabular}

Fonte: Dados da pesquisa (2020)

Quanto ao perfil das empresas, a empresa A é formada por dois sócios e atua no desenvolvimento de software para gestão de empresas. Ela conta com 39 empregados, distribuídos em quatro áreas: comercial, desenvolvimento, financeiro e recursos de treinamento à distância. A empresa foi fundada em 2006, por três sócios, um deles foi o investidor que após dez anos se retirou da sociedade. Essa empresa foi criada após o desenvolvimento de um produto que durou três anos. A empresa $\mathrm{C}$ está reestruturando a oferta de seu produto, após uma fase de declínio, que resultou na redução de funcionários,

Perspectivas em Gestão \& Conhecimento, João Pessoa, v. 11, número especial, p. 131-145, mar. 2021. 
sendo no momento da entrevista contava com nove funcionários. Por fim, a empresa $D$, tendo iniciada a sua atividade em 2010, conta com trinta e cinco funcionários e está em fase de crescimento.

Tabela 2 - Dados do perfil das empresas

\begin{tabular}{l|l|l|l}
\hline Caso & Ano de criação & $\begin{array}{c}\text { Número de } \\
\text { funcionários }\end{array}$ & Sócios \\
\hline A & 2000 & 39 & 2 \\
\hline B & 2006 & 25 & 2 \\
\hline C & 2006 & 9 & 4 \\
\hline D & 2010 & 35 & 2 \\
\hline
\end{tabular}

Fonte: Dados da pesquisa (2020)

As categorias derivadas da codificação do corpus do texto abrangem: a 'importância da inovação', 'as variáveis internas para inovação', sendo elas redes, projetos e prêmios e cultura; as 'variáveis externas', mencionadas a partir de necessidades de políticas de apoio ao setor e, por fim, as 'dificuldades para inovar'.

Importância da inovação. Os dados da pesquisa mostram como as empresas consideram a inovação em suas atividades. O Quadro 4 apresenta excertos que foram selecionados das entrevistas para evidenciar como cada empreendedor percebe a inovação para o seu empreendimento.

Quadro 4- Importância da inovação para os empreendedores

\begin{tabular}{|l|l|}
\hline Empreendedor & Depoimento \\
\hline A & $\begin{array}{l}\text { "Nós respiramos inovação. Como a empresa tem como referência promover } \\
\text { excelência na gestão, nós estamos aqui com foco em melhoria. [...] nós } \\
\text { temos a inovação disruptiva [segundo o manual da Oslo], que é a mais } \\
\text { conhecida, vamos fazer algo que ninguém fez, mas existe a inovação } \\
\text { incremental, que é aquela inovação que você vai melhorando o processo ou } \\
\text { alterando a forma de fazer e melhoria de processo está muito ligado a } \\
\text { tecnologia. Por exemplo, temos dentro da própria plataforma um painel de } \\
\text { gestão da empresa onde o gestor pode ver indicadores, sejam financeiros, } \\
\text { de estoque, comerciais e ele consegue avaliar o seu desempenho e verificar } \\
\text { o que que ele precisa fazer de melhoria. [...] nós também utilizamos a nossa } \\
\text { ferramenta e temos dentro de painel de serviços [site] [...] para atender } \\
\text { necessidades [de inovação] dos clientes ou para fazer melhoria de processo } \\
\text { interno aqui dentro da empresa". }\end{array}$ \\
\hline "A empresa respira inovação, qualidade de vida e respira colaboração. Nós \\
temos um molho especial, mas o molho especial é o que a gente passa para \\
nossa comunidade, que é colaboração, conhecimento e pró atividade. Esses \\
três ingredientes [fazem um] molho especial, não importa o produto, você \\
sempre vai encontrar esse tempero no nosso atendimento, no nosso \\
produto, na forma de trabalhar".
\end{tabular}

Fonte: Dados da pesquisa (2020) 
Nota-se, pelos excertos extraídos das entrevistas, que a inovação é, de fato, algo inerente às empresas. Todavia, as percepções acerca da inovação são diferentes. $O$ primeiro empreendedor (empreendedor A) faz referência à inovação incremental, e com isso, a inovação nessas empresas se situa entre básica e intermediária, conforme a classificação de Miranda e Figueiredo (2010).

O segundo empreendedor fez referência à qualidade de vida, expressando que a empresa tem uma cultura organizacional que integra os valores colaboração, conhecimento e pró-atividade. Nesse aspecto, é importante salientar que a cultura é um dos elementos inerentes ao processo de gestão da inovação em diversos modelos, como por exemplo, os modelos de Bezerra e Marques (2019), Leo e Tello-Gamarra (2020) e Salazar (2020).

O empreendedor $D$ salientou, por exemplo, a importância da criatividade como uma forma de obter otimização de resultados. Para esse empreendedor, a inovação é uma condição para aumentar o faturamento de sua empresa. A inovação representa para ele uma fonte de competitividade e uma perspectiva de aumento de faturamento. Para o empreendedor $\mathrm{C}$, a inovação é necessária para competir no mercado, principalmente com as grandes empresas. A criatividade é um dos elementos da inovação no modelo de Bezerra e Marques (2019).

Variáveis internas para inovação. Os empreendedores citaram como sendo condições internas importantes para as empresas inovarem: a participação na rede que integram; o desenvolvimento de projetos, prêmios e metas; retenção de pessoal e cultura de inovação.

A 'participação na rede que integram', diz respeito a como as empresas estão envolvidas em um arranjo municipal. Nesse sentido, as empresas salientaram a importância do associativismo. Para os empreendedores, as redes contribuem para qualificação dos empresários e dos empregados. Entre as atividades que citaram constam: palestras e visitas a outras empresas visando a transferência de conhecimento, as quais serviram como fonte de criação de projetos e de mudanças de processos nas empresas. Além disso, os empreendedores citaram a estratégia do arranjo de atrair desenvolvedores de outros estados brasileiros, a fim de obter pessoas com qualificação e competências. Para isso, eles mencionaram também o apoio de universidades e faculdades locais (cinco ao todo), que contribuem com a formação de mão de obra de elevada qualidade. Outra contribuição para os recursos humanos citada foi a do Centro Municipal de inovação, por meio de bolsas, bem como do Serviço Nacional da Indústria (SENAI). Esse resultado também corrobora com a variável networking, apresentada na dimensão inovação do modelo de Bezerra e Marques (2019).

Salienta-se, ainda, que três empresas mencionaram o apoio do Serviço Brasileiro de Apoio às Micro e Pequenas Empresas (SEBRAE), no tocante a programas de treinamento e de exportação, eventos e linhas de subsídio para certificação internacional. Além disso, duas empresas salientaram o apoio financeiro da Federação das indústrias e o Programa PEIEX de incentivo à exportação de produtos e conquista de mercados.

Para o 'desenvolvimento de projetos, prêmios e metas', o empreendedor A fez menção a um projeto que está sendo desenvolvido, que é um portal de inovação. Esse portal é uma plataforma que integra ferramentas para as empresas na forma de ensino a distância. 0 empreendedor $B$ destacou as premiações de inovação obtidas em nível estadual e premiação na área de Recursos Humanos. $O$ empreendedor $A$ salientou a importância do estabelecimento de metas para descobrir novas formas de trabalhar, ganhar mercado e expandir. Para esse empreendedor, o desenvolvimento de produtos: "é como um jogo, que você vai passando as fases. Hoje a gente tem produto no mercado, a gente tem receita, a gente tem as metas, mas a gente sabe que o jogo como um todo é gerar um valor diferente para a sociedade, é resolver algum problema e resultado" (Empreendedor A).

Perspectivas em Gestão \& Conhecimento, João Pessoa, v. 11, número especial, p. 131-145, mar. 2021. 
Considerando a 'retenção de pessoal e cultura de inovação', as empresas mencionaram a importância da valorização do profissional que trabalha na empresa, por meio de retenção de pessoal e de políticas de recursos humanos. Levallet e Chan (2019) salientam a importância de reter empregados para gerir o conhecimento, principalmente o conhecimento tácito. Isso está associado aos efeitos negativos da rotatividade sobre a memória da organização e sobre níveis de produtividade (JIANG; BAKER; FRAZIER, 2009). A retenção de pessoal, enquanto resultado desta pesquisa, corrobora com a dimensão Gestão do conhecimento no modelo de Bezerra e Marques (2019).

O papel da cultura, comentado anteriormente, foi citado por uma das empresas, como pode ser verificado: "Você tem que ter uma cultura que tua equipe respira aquilo, que eles vivenciam aquilo e isso faz o que? Isso reflete no mercado, reflete no cliente, reflete nos investidores, em como o mercado te vê" (Empreendedor B). Kaufmann et al. (2019) salientam que liderança, cultura e estratégia são importantes para a melhoria de capacidades inovativas de empresas de software.

Variável externa para inovação: Políticas Públicas. Apenas um aspecto foi mencionado como variável externa para assegurar a inovação e por apenas uma das empresas, que enfatizou a necessidade de políticas públicas para empresas do setor, de modo a não ficarem totalmente dependentes de investidores, como pode ser observado no trecho abaixo:

As pequenas empresas ou as startups sofrem muito com a falta de dinheiro. Existem muitos investidores, só que o investidor ele vem com o dinheiro e ele quer o resultado a curto prazo e startup tem essa promessa de crescer e crescer muito rápido, em pouco tempo, mas a gente sabe que é um risco muito grande também, que não é toda ideia que vai crescer....Então para as pequenas startups terem subsídios, ter financiamentos e que também não faça com que o empresário tenha que colocar $100 \%$ de sua empresa na mão de um investidor..." (Empreendedor C)

Essa visão corrobora com as diretrizes de inovação da OECD (1996) para empresas intensivas em conhecimento, que prescindem de políticas governamentais. O setor obteve subsídios governamentais nacionais para atuação, o que foi mencionado por apenas uma das empresas, que lamentou o fim dele. Leo e Tello-Gamarra (2020) apontam como determinantes externas da inovação, além de políticas e instituições públicas, os atores (competidores, clientes e fornecedores).

Dificuldades para inovar. Outro aspecto importante sobre a inovação que aparece nos depoimentos dos empreendedores está associado a dificuldades que eles enfrentam para buscar inovação. Ela figura no depoimento de três dos entrevistados, conforme apresentado no Quadro 5. Os empreendedores em questão enfatizaram que o processo de inovação é dependente de recursos humanos preparados. Outro desafio para essas pequenas empresas é representado pelo lançamento do produto no mercado.

Quadro 5- Dificuldades para inovar segundo os empreendedores

\begin{tabular}{|l|l|}
\hline Empreendedor & Dificuldade \\
\hline B & "Fazer software é caro porque a base dele é criação humana, não dá \\
& para você automatizar a produção de software como você faz coloca \\
& robôs na linha de produção de veículos e se você não tem nem a mão de \\
& obra preparada você ainda tem que formar as pessoas para criarem o \\
& produto. Isso faz com que o tempo seja maior e a tecnologia é muito \\
& rápida. Se você demora para fazer o produto você perdeu o time do \\
& mercado e aí seu produto não serve para mais nada. Então o que \\
& dificulta bastante é processo de inovação maduro que tenha ali a mão \\
de obra disponível, com recurso disponível, com a ideia disponível no & tempo certo. Isso é o grande gargalo". \\
\hline C & "Dificuldade para lançar produto no mercado". \\
\hline
\end{tabular}

Perspectivas em Gestão \& Conhecimento, João Pessoa, v. 11, número especial, p. 131-145, mar. 2021. 


\begin{tabular}{|l|l|}
\hline D & $\begin{array}{l}\text { “Dificuldade para ter pessoas engajadas e no nosso setor, venda de } \\
\text { software é complexa, não é fácil, talvez essa seja uma das maiores } \\
\text { dificuldades que a área de TI [Tecnologia da Informação] tem". }\end{array}$ \\
\hline
\end{tabular}

Fonte: Dados da pesquisa (2020)

O empreendedor ' $B$ ' salientou a dificuldade relativa ao tempo para desenvolvimento do produto, que precisa ser curto. Esse mesmo empreendedor afirmou que um prazo desejável seria de três a seis meses, sendo este um dos critérios que utiliza na hora de selecionar ideias inovadoras. $\mathrm{O}$ empreendedor ' $\mathrm{C}$ ' relatou a dificuldade que tem em lançar um produto inovador no mercado, e, ainda, para o empreendedor ' $D$ ', a dificuldade é encontrar pessoas desenvolver e vender produtos inovadores.

Em síntese, os resultados da pesquisa mostraram que a inovação para as pequenas empresas de software que participaram da pesquisa representa um esforço por parte delas para estruturar condições internas, especificamente associadas à criação de uma cultura, à retenção de pessoal e ao desafio de desenvolverem produtos em tempo curto para colocação no mercado. Para isso, elas buscam desenvolver projetos e obter premiações em busca de visibilidade. Os empreendedores consideram que políticas governamentais são importantes para inovar e para amenizar as dificuldades que encontram, associadas ao desafio de criar conhecimento e inovação para um mercado dinâmico, competindo com grandes empresas. Comparando os resultados da pesquisa com as dimensões de avaliação da inovação do modelo de Bezerra e Marques (2019) observa-se que a maioria dos aspectos identificados no referido modelo foram encontradas nas empresas, evidenciando que elas criam valor e inovação para outras empresas e isso resulta de um posicionamento delas face à inovação. A comparação das dimensões encontra-se no Quadro 6.

Quadro 6- Dimensões avaliativas do modelo de Bezerra e Marques (2019) e resultados da pesquisa Inovação

Estratégia com valores inovativos, desempenho monitorado por meio de plataformas. Empreendedores exercem papel de liderança junto as equipes e apoiam novas ideias com tempo de maturação curto. Equipes tem autonomia para desenvolvimento de projetos. Quanto à estrutura e mobilidade nos cargos esse aspecto não apareceu nos depoimentos. Processos formais de gerenciamento de projetos e planejamento do ciclo de desenvolvimento dos projetos. Estratégias explícitas para a retenção de talentos, mencionada por entrevistados e observada em uma das empresas que implementou uma parede da fama para valorização dos empregados mais antigos. Valorização de networks por empreendedores, vínculos e parcerias com universidades, institutos de pesquisa, SEBRAE, SENAI, FIEP. Não foi possível identificar se os funcionários sabem da importância das redes externas como forma de sustentação da competitividade.

Conhecimento Armazenamento e compartilhamento de informações

As informações estão documentadas e organizadas em espaços virtuais de acesso geral, compartilhadas entre os desenvolvedores, que usam os recursos de acesso e compartilhamento dos sistemas de informações. As empresas têm mecanismos formais para se compararem com a concorrência. A avaliação do desempenho é uma atividade de aprendizagem e é estimulada com prêmios. O aprendizado é uma responsabilidade integral e diária de todos. Produtos e serviços são percebidos pelos clientes como inovadores, empresas buscam criatividade e agilidade, principalmente para enfrentar a concorrência com grandes empresas. A visão geral está claramente comunicada, expressa em valores. A estrutura organizacional estimula a interação e o compartilhamento de conhecimento. O comportamento coletivo e a colaboração são estimulados. Uma das empresas têm uma sala ampla com café e espaços decorados para integração e compartilhamento. A aquisição e o compartilhamento de conhecimento são práticas formais. Existem processos formais para melhores práticas e busca por premiações que reforcem a visibilidade em melhores práticas. O conhecimento é

Perspectivas em Gestão \& Conhecimento, João Pessoa, v. 11, número especial, p. 131-145, mar. 2021. 
rapidamente aplicado na solução de problemas.

Fonte: Dados da pesquisa (2020)

As empresas não mencionaram práticas de vigilância tecnológica, que segundo Salazar (2020) são importantes para empresas que atuam com conhecimento e inovação. Outro aspecto que não foi mencionado pelas empresas foi a transferência de conhecimento por parte de universidades, como salientam Diniz et al. (2020). Os empreendedores mencionaram a relação com as universidades apenas como formadoras de mão de obra.

Em síntese, a inovação mostrou-se relevante para empresas do setor de desenvolvimento de software, em particular os pequenos empreendimentos, como apontam os dados desta pesquisa. Entretanto, salienta-se que, embora todos os entrevistados reconheçam as contribuições da inovação para a sustentabilidade de seus negócios, buscando fomentar essas ideias entre seus pares e clientes, eles não mencionaram parcerias para desenvolvimento de pesquisas em conjunto com universidades, o que contribuiria para inovações radicais e não apenas incrementais como as produzidas por elas. De modo geral, os resultados da pesquisa permitem afirmar que essas empresas alinham o discurso com as práticas da inovação, legitimando-as vender criação de valor para outras empresas a partir do lema do 'faça o que eu digo e faça o que eu faço'.

\section{CONSIDERAÇÕES FINAIS}

Esta pesquisa teve como objetivo compreender como pequenas empresas de software lidam com a questão do conhecimento e da inovação e qual o apoio recebido para buscar inovação. Por meio de um estudo realizado junto a quatro empresas pequenas que participam de um arranjo municipal constatou-se que as empresas atribuem importância ao conhecimento e à inovação e que consideram necessárias ações internas e externas. Entre as ações internas, o estudo mostrou importância das redes, cultura, retenção de pessoas, desenvolvimento de projetos e busca de premiações. Quanto à ação externa, foi citada a necessidade de política para o setor.

Os resultados da pesquisa, corroboram amplamente com dimensões e preceitos de inovação e conhecimento apontados em estudos anteriores. Ainda que este estudo não apresente novos elementos para o desenvolvimento da inovação, ele é importante para melhor compreensão dos desafios e limitações de pequenas empresas de software em relação à gestão interna da inovação e do conhecimento e para produção de inovação para o mercado.

As conclusões são limitadas às empresas que participaram do estudo, não propiciando generalização. Além disso, convém salientar que os resultados obtidos refletem apenas a visão dos empreendedores. Sugere-se que estudos futuros avaliem a inovação a partir do discurso dos funcionários e dos colaboradores sem vínculo empregatício. Outra sugestão é a de estudos com empresas que não participam de arranjos, com o intuito de ampliar as conclusões.

\section{REFERÊNCIAS}

ASSOCIAÇÃO BRASILEIRA DAS EMPRESAS DE SOFTWARE. Mercado Brasileiro de Software: panorama e tendências. Recuperado em 18 agosto, 2018 de <http:// central.abessoftware.com.br/Content/UploadedFiles/Arquivos/Dados\%202011/ af_abes_publicacao-mercado_2018_small.pdf $>$.

BARDIN, L. Análise de conteúdo. 4. ed. Lisboa: Edições70, 2011.

Perspectivas em Gestão \& Conhecimento, João Pessoa, v. 11, número especial, p. 131-145, mar. 2021. 
BASAÑEZ, J. A. Metodología de Evaluación y Gestión del Conocimiento dinámico por processos utilizando como soporte TIC el Entorno Colaborativo de Trabajo basado en el modelo de creación de Conocimiento de Nonaka-Takeuchi: Caso de estúdio en el área de Gestión de proyectos de I+D+i em institución avanzada en Conocimiento. 190 f. 2014. Tese (Doutorado) - Curso de Gestión del Conocimiento, Universidad de Córdoba, Córdoba.

BEZERRA, C.; MARQUES, D. C. Gestão do conhecimento, inovatividade, criatividade e desempenho inovador em empresas de saúde. Perspectivas em Gestão \& Conhecimento, João Pessoal, v.9, n.2, p. 56-84, 2019. DOI: http://dx.doi.org/10.21714/2236-417X2019v9n2p56.

DINIZ, D. M.; MENDONÇA, F. M.; SIQUEIRA, P. H. L.; SANTOS, M. G. (2020). Transferência de conhecimento entre universidade e empresa (U-E): influência das condições universitárias. BASE - Revista de Administração e Contabilidade da Unisinos v.17. doi: 10.4013/base.2020.171.03

GASQUEZ, A. H.; MACHADO, H. P. V.; URPIA, A. G. Experiências de internacionalização de pequenas empresas de software e conhecimentos obtidos. Internext, v.15, n. 2, p. 18-36, 2020.

GOSWAMI, A. K.; AGRAWAL, R.K. (2018). A reflection on knowledge sharing research: patterns and trends. Vine Journal of information and knowledge Management Systems, v.48, n.3, p.352-372, 2018.

IBEH, K.; KASEM, L. The network perspective and the internationalization of small and medium sized software firm from Syria. Industrial Marketing Management, v. 40, p.358-367, 2011.

JIANG, B; BAKER, R. C.; FRAZIER, G. V. An analysis of job dissatisfaction and turnover to reduce global supply chain risk: evidence from China. Journal of Operations Management, v.27, n.2, p. 169-184, 2009.

KAUFMANN, E. FAVRETTO, J., FILIPPIM, E. COHEN, E. Relationship Between the Organizational Memory and Innovativity: The Case of Software Development Companies in The Southern Region of Brazil. JISTEM J. Inf. Syst. Technol. Manag., v. 16, 2019.

LAUKKARINEN, T., KUUSINEN, K., MIKKONEN, T. Regulated software meets DevOps, Inf. Softw. Technol., v. 97, p. 176-178, 2018.

LEITE, Y. V. P.; MORAES, W. F. A. M. The ability to innovate in international entrepreneurship. Revista de Administração de São Paulo, v. 50, n.4, p. 447-459, 2015.

LEO, RICARDO M; TELLO-GAMARRA, J. Drivers da inovação em serviços: proposição de um modelo teórico. Revista de Administração da Mackenzie, v.21, n.3, 2020. doi:10.1590/16786971/eRAMR200143.

LEVALLET, N.; CHAN, Y. E. Organizational knowledge retention and knowledge loss. Journal of Knowledge Management, v.23, n.1, p. 176-199, 2019.

MACHADO, H. P. V. Crescimento de Empresas na Perspectiva de Pequenos Empreendedores de Base Tecnológica. Rev. Adm. Contemp., v.22,n.6, p.817-840, 2018.

Perspectivas em Gestão \& Conhecimento, João Pessoa, v. 11, número especial, p. 131-145, mar. 2021. 
MASSAGO, Y., TANNO, D. R., BALANCIEIR, R., LEAL, G. C. L., GALDAMEZ, E. V. C., HUZITA, E. Influência dos aspectos socioculturais em um modelo de maturidade para gestão do conhecimento. Revista Brasileira de Sistemas de Informação, v. 12, n.4, p. 64-97, 2019.

MIRANDA, EDUARDO C.; FIGUEIREDO, P. N. Dinâmica da acumulação de capacidades inovadoras: evidências de empresas de software no Rio de janeiro e em São Paulo. Rev. Adm. Empres., v.50, n.1, p.75-93, 2010.

NAWINNA, D. P. A model of Knowledge Management: Delivering competitive advantage to small \& medium scale software industry in Sri Lanka, 2011 6th Int. Conf. Ind. Inf. Syst. ICIIS 2011, pp. 414-419, 2011.

OECD (1996). The Knowledge-based economy. Paris, 45 p. Disponível em: https://www.oecd.org/officialdocuments/publicdisplaydocumentpdf/?cote=OCDE/GD\%2896\% 29102\&docLanguage $=E n$

OECD. Oslo Manual 2018: guidelines for collecting and interpreting innovation data. 4. ed. Paris: OECD Publishing, 2018.

RIVERO, J. A. G. Administración del conocimiento y modelos de calidad como estratégias competitivas en las pequeñas y las medianas empresas de software. 2010. $130 \mathrm{f}$. Tese (Doutorado en Ciencias Con Especialidad Em Administración) - Instituto Politécnico Nacional, Ciudad de México, 2010.

ROBILLARD, P. N. The Role of Knowledge in software development. Communications of the ACM, v.42, n.1, p. 87-92, 1999.

SALAZAR, M. P.R. MIIGO- Modelo-innovacion-tecnologia-y-conociemiento.pdf. Universidad Ean, 2020.

SAMPIERI, R. H.; COLLADO, C. F.; LUCIO, M. D. P. B. Metodologia de pesquisa. Porto Alegre: Penso, 2013.

SCHUMPETER, J. A. The theory of economic development. Cambridge: Transaction Books, 1934.

YIN, R. K. Estudo de caso: planejamento e métodos. 5. ed. Porto Alegre: Bookman, 2015.

Recebido em/Received: 05/02/2021 | Aprovado em/Approved: 10/03/2021

Perspectivas em Gestão \& Conhecimento, João Pessoa, v. 11, número especial, p. 131-145, mar. 2021. 